\title{
Why Whine ABout Wining And Dining?*
}

\author{
Benjamin E. HeRmalin ${ }^{\dagger}$
}

\begin{abstract}
Given potential abuse, conflicts of interest, and other issues, why do companies routinely pay for their managers to entertain the managers of other firms and allow their own managers to be so entertained? An answer that such practices facilitate inter-firm cooperation is incomplete because it fails to address why companies can't or don't induce such cooperation directly via their own incentive systems. This paper addresses these issues. It shows, inter alia, that even when firms can induce cooperation via their own incentive systems, they will do better obtaining that cooperation via crossfirm entertaining and other favor granting. This remains true even if "entertainment" budgets are subject to corruption, including excessive use or potential embezzlement. Furthermore, the results are wholly independent of any favorable tax treatment such practices may receive.
\end{abstract}

Keywords: Inter-firm cooperation, incentives to help, gift exchange

JEL Classification: D82, D86, L14, L24, M52

\footnotetext{
* This paper derives from a project begun with the late Tony Naughton. The financial support of the Thomas and Alison Schneider Distinguished Professorship in Finance and the hospitality of Nuffield College, University of Oxford, are gratefully acknowledged.

${ }^{\dagger}$ University of California • Department of Economics • 530 Evans Hall \#3880 • Berkeley, CA 94720-3880 • email: hermalin@berkeley.edu.
}

Date: August 6, 2014 


\section{INTRODUCTION}

Corporations spend significant amounts on entertaining and the provision of other gifts and benefits to personnel of other firms. ${ }^{1}$ While the rationale for such practices might seem obvious - corporations doing this expect to generate more business, better cooperation, or other profitable quid pro quo from those being wined and dined - two questions immediately arise: (i) why do firms let their own managers be the beneficiary of such largesse if its purpose is to induce the managers to pursue actions desired by other firms? And (ii) if firms benefit from better cooperation and otherwise smoother business relations, why don't they directly provide their own managers with the necessary incentives to be cooperative? Indeed many organizations, principally governmental agencies, impose restrictions on the gifts and other favors that their employees can receive from outside sources, ${ }^{2}$ presumably to eliminate at least the perception of conflict-of-interest problems. But why don't all organizations do this?

This paper seeks to rationalize why firms (shareholders) would find it in their interest to permit their managers to both wine and dine and be wined and dined. It does so in an environment without taxes or other governmental policies that could lead firms to prefer to pay in-kind or via fringe benefits. ${ }^{3}$ Further, it is assumed that the firms could, if they wished, provide incentives directly to their managers that would induce the same level of cooperation as wining and dining do. Nonetheless, I show that wining and dining is a less expensive way for firms to provide such incentives. Indeed, if wining and dining is "perfect" - that is, immune to abuses such as expense-account fraud and excessive generositythe firms can achieve the first-best outcome. Even if wining and dining is not perfect, so that abuses can arise (such as, potentially, expense-account fraud), I show that firms still do better when they can wine and dine (more generally, provide gifts) than they would were such practices unavailable to them.

The key insight driving the results is that, while shareholders (the principal) can provide incentives, those incentives are necessarily expensive because shareholders cannot directly observe whether their managers are behaving cooperatively. Consequently, managers capture information rents under standard incentive contracts. A manager, however, directly observes whether her counterparty is being cooperative. Hence, it is possible that, in the quid pro quo implicit (relational) contract between themselves, the managers can avoid paying information rents. At the same time, though, giving the managers discretion over

\footnotetext{
${ }^{1}$ According to a 2011 estimate by J.P. Morgan, US corporate expenditure on travel and entertainment ( $\mathrm{T} \& \mathrm{E}$ ) was $\$ 157$ billion annually. Of that, entertainment per se was about $5 \%$ ( $\$ 7.85$ billion). Other categories that could presumably include forms of wining \& dining ("restaurant meals," "meetings \& events," "other non-travel spending") were more than an additional $20 \%$ (\$31.4 billion). Such figures do not include other favors, such as hiring relatives, providing discounts on merchandise, etc.

${ }^{2}$ For example, in the Us, the Code of Federal Regulations (CFR) imposes various limits on gifts, including meals, that executive branch employees can receive (see 5 CFR Part 2635).

${ }^{3}$ See Clotfelter (1983) for a model and an analysis of why tax policy might encourage firms to increase their travel and entertainment budgets.
} 
the entertainment budget could create new agency problems. If new agency problems aren't created (managers are sufficiently honest and auditing is sufficiently good), then, as noted, the shareholders can achieve the first best. Even if agency problems are generated, circumstances exist such that they are less costly than the information rent the shareholders would otherwise have to pay were there no wining and dining. At the extreme, however, the agency problems created by wining and dining are so severe as to eliminate the benefits of wining and dining. Yet, even at this extreme, the shareholders would be no worse off allowing wining and dining than they would be were they to prohibit it.

The model, detailed in the next section, presumes two firms interact repeatedly. In any given period, an opportunity may arise in which one firm would benefit if the manager of the other was cooperative (provided what I call "assistance"). Managers know whether assistance was provided or not, but shareholders only know whether their firms achieved success or not for that period. I focus on settings in which surplus is maximized only if all opportunities ("projects") are pursued and assistance is always provided when it will be beneficial. Although the shareholders may be able to induce surplus maximization absent wining and dining, they cannot capture all that surplus themselves due to the information rents they must leave their managers. Hence, either they elect not to maximize surplus (forgoing some surplus in order to reduce the information rent) or they fail to realize first-best profits.

In Section 5, I allow for "perfect" wining and dining: managers commit to wine and dine on a quid pro quo basis only and they cannot embezzle any of their entertainment budget. The first feature, commitment to quid pro quo, rules out collusion among the managers. The alternative, which is they spend their entertainment budgets on each other every period regardless of whether assistance was required, is explored in Section 6. Although such collusion raises the shareholders' costs, it still proves a less expensive means of providing incentives to cooperate (provide assistance) than doing so via an incentive contract. The reason is that, under an incentive contract alone, if the managers ceased to cooperate, it would be some time, in expectation, before they were effectively punished: if, by luck, a manager doesn't require assistance in future periods, she captures a rent. In contrast, with wining and dining, even if the managers collude, the punishment for not cooperating is applied immediately. It is, therefore, more severe and, thus, a better deterrent; hence, the rent paid the managers can be less. The other feature of perfect wining and dining, no embezzlement, is relaxed in Section 7. In that section, it is assumed that a manager can pocket the entertainment budget given her by her firm, without detection or punishment from her firm. On the other hand, her counter-party will know he wasn't wined or dined when he should have been and he can punish her by withholding future cooperation. Hence, on the equilibrium path, entertainment budgets are not embezzled; yet ensuring this will necessitate managers receiving some rents, so the shareholders will be unable to achieve the first best. Nonetheless, the shareholders still do better than they would were wining and dining impossible.

Although the analysis is couched in terms of wining and dining, it should be understood that the transfers between agents need not be gifts or favors per 
se. They could, equivalently, be discretionary payments that one firm makes to a second when the second has provided some difficult-to-verify service or when determining whether that service was of sufficient quality is wholly subjective. For the model to apply, discretion over these payments is delegated to the firms' managers and these inter-firm payments must, in turn, be paid to the assisting manager as a bonus.

To the best of my knowledge, there is no prior literature on situations in which principals of separate organizations seek to provide their own agents incentives to cooperate by, effectively, delegating to the agents the ability to monitor and compensate each other. At the same time, various related situations have been explored, primarily in settings with a single principal who has motives to encourage cooperation and delegate supervision (i.e., single-organization settings). For example, Itoh (1991) considers how a single principal induces her agents to assist each in a static (one-shot) setting. Che and Yoo (2001) consider, inter alia, how a single principal induces cooperation among her agents in a dynamic (repeated) setting. ${ }^{4}$ Neither paper considers the principal's delegating to the agents the authority to make discretionary payments to each other.

Starting with Tirole (1986), there is a sizable literature concerned with issues of collusion among agents in settings where one agent monitors (supervises) another (see Mookherjee, 2013, for a survey). In that literature, monitoring is unidirectional; here, it is bidirectional. Additionally, the focus of that literature has been on within-firm situations. Arguably, the related literature on corruption (see Banerjee et al., 2013, for a survey) is an exception; there two "organizations," a bureaucracy and an outside entity, are at play. At the same time, models of corruption are quite different than the analysis here: although the outside entity provides a gift (bribe) to the bureaucrat (agent) to induce his cooperation (assistance), such actions are typically undesired by his principal (head of the agency or the public).

This paper has a tangential relationship to the game-playing-agents literature (see Katz, 2006, for a partial survey and critique). Like that literature, here principals give their agents contracts that affect how the agents interact. ${ }^{5}$ That literature, though, is focused on principals (firm owners) engaged in product-market competition. Although such principals might want to induce cooperation (e.g., collusion on price), any overt actions to do so (e.g., having the executive of one firm wine $\&$ dine an executive of another) would typically be illegal under prevailing antitrust law. A further difference is that, as far as I'm aware, game-playing-agent models have considered only static settings. Here, in contrast, repeated interaction is a critical component of the model.

\footnotetext{
${ }^{4}$ Malcomson $(2013, \S 8)$ surveys some of relevant literature on cooperation in repeated games. That literature, however, considers a single principal only.

${ }^{5}$ As Katz $(1991,2006)$ points out, an important issue in this literature is whether or not the principal-agent contract signed by one firm is observable to the other (and vice versa) at the time the agents interact. Katz argues that unobservable contracts are the more realistic assumption. In what follows below, a given principal-agent contract should be assumed to be the private information of the relevant principal-agent pair; however, in equilibrium, all parties will correctly anticipate the contracts being used.
} 
The paper's organization was largely set forth above. In addition to the sections already discussed, there is a brief concluding section, Section 8, which, inter alia, briefly considers alternative explanations for wining \& dining.

\section{The Model}

There are two ex ante identical firms.

A firm's shareholders employ a manager for an indefinite length of time. Time is divided into discrete periods, indexed by $t$, with the current period corresponding to $t=0$. The manager is risk neutral, with a per-period utility function $Y-C$, where $Y$ is her compensation, a monetary amount, and $C$ is her private cost of taking actions. The manager's outside option (reservation utility) is normalized to zero. Assume the manager is protected by limited liability: she cannot "receive" negative pay. ${ }^{6}$

In each period, the manager has a project (alternatively, task or opportunity) she can pursue. A project can be either straightforward (simple) or complex (hard). A simple project is easily within the manager's capabilities and she can complete it at low cost, $c_{\ell}$. If the project is complex (at least for the particular manager), then completing it on her own entails an additional cost of $\Delta$; that is, if she completes a complex project on her own, her total cost is $c_{h} \equiv c_{\ell}+\Delta$ (the subscript $h$ denoting a hard or high-cost project). When the project is complex, an alternative is to obtain assistance from the other firm's manager, who is more capable (alternatively, has access to better resources or some other advantage); his cost of providing assistance is $a$, where $a<\Delta .{ }^{7}$ Receiving assistance means the recipient manager avoids incurring $\Delta$ (i.e., her cost is just $c_{\ell}$ ).

As one of many possible examples, the "project" could be delivery of intermediate goods from one firm to the other. With probability $1-\phi$, it is straightforward to make this delivery in a timely fashion; with probability $\phi$ it would cost the manager an additional $\Delta$. The other manager's cost of dealing with delayed delivery is $a$ and "assistance" constitutes being willing to take delayed delivery. Conversely, the other manager finds it straightforward to pay immediately for delivery with probability $1-\phi$, but with probability $\phi$ he would incur additional costs of $\Delta$ to arrange an immediate payment. Assistance to him would be agreeing to accept delayed payment. ${ }^{8}$

\footnotetext{
${ }^{6}$ The assumption of limited liability can justified by appeal both to labor law and the right of individuals to declare personal bankruptcy. Sappington (1983) introduced the use of limited liability to make the moral-hazard problem relevant when principal and agent are risk neutral.

${ }^{7}$ If the model is extended, so the quality of the service is discretionary and its assessment subjective, then think of "assistance" as being either high quality, which costs its provider $a$ and reduces the assisted manager's costs by $\Delta$, or low quality, which costs its provider 0 and has no effect on the "assisted" manager's costs; that is, the provision of low-quality assistance is the same as declining to provide assistance at all.

${ }^{8}$ Given the asymmetric roles in this example, one might ask whether the cost and probability parameters should be the same for the two firms. Allowing for asymmetric parameters would complicate the analysis without, as will be evident, affecting its substantive conclusions; hence, for the sake of brevity and simplicity, the parameters are assumed to be symmetric.
} 
Whether a given period's project will be complex (high cost) or simple (low cost) is something the manager learns before pursuing it. This is her private information. It is, though, common knowledge that the project will be complex with probability $\phi \in(0,1)$. Project type is identically and independently distributed across time.

If the project is pursued, it returns a financial benefit $b$ to shareholders (possibly in expectation) regardless of its complexity. Assume that $b>c_{\ell}$ and $b>c_{\ell}+a$; in other words, it is efficient to pursue simple projects and, if assistance is forthcoming, complex projects as well. All this is common knowledge.

With regard to their firm's own project, shareholders can observe - and verify - if the manager has pursued it or not. Hence, the manager's payment can be made contingent on whether she has pursued a project. Because they don't observe how costly the project is, they cannot make her pay contingent on the realization of $c$. Assume that they cannot observe whether their manager provides assistance to the other firm or was provided assistance. Hence, a manager's compensation cannot depend directly on whether she gave or received assistance. To summarize, a manager's per-period compensation has the form

$$
Y=\left\{\begin{array}{l}
y(0), \text { if no project pursued } \\
y(1), \text { if project pursued }
\end{array} .\right.
$$

The shareholders can also condition a manager's continued employment on whether or not a project is pursued. If the shareholders dismiss a manager for not pursuing a project, assume they hire a new manager from an inexhaustible pool of would-be managers.

Assume the shareholders possess all the bargaining power. In other words, they can offer their manager a contract each period on a take-it-or-leave-it basis. The manager accepts if her equilibrium expected utility exceeds her reservation utility (i.e., zero) and she rejects it otherwise. If she rejects, the shareholders immediately enter into negotiations with another managerial candidate. If she accepts, as she will on the equilibrium path, she then learns how costly her own firm's project is that period. Next she possibly seeks the assistance of the other firm's manager and, likewise, may receive a request for assistance. Managers make their assistance decisions. Next, each manager decides whether to pursue her own firm's project. Finally, outcomes are realized, payments made as stipulated in the relevant contracts, and the period ends.

Assume there is a common per-period discount factor, $\delta \in(0,1)$, that all parties use when discounting future receipts and payments.

\section{Benchmark: A Firm in Isolation}

Suppose, contrary to the situation of interest, there was no possibility of assistance; that is, if a manager pursues a project, the cost to her is necessarily the $c$ realized that period.

There are two cases to consider. The first is $b \leq c_{h}$; that is, it is inefficient to pursue the project if it is high cost. Hence, maximum per-period surplus is 
$b-c_{\ell}$ if $c=c_{\ell}$ and 0 if $c=c_{h}$. The shareholders can generate this surplus by offering the compensation contract:

$$
y(\chi)=\left\{\begin{array}{l}
0, \text { if } \chi=0 \\
c_{\ell}, \text { if } \chi=1
\end{array},\right.
$$

where $\chi=0$ indicates no project was pursued and $\chi=1$ indicates one was. If she accepts this contract, the manager's best response is to pursue the project when it is low cost and not to pursue it otherwise. Regardless of the realized cost, this strategy yields her utility 0 , which equals her reservation utility. It is, thus, a best response for her to accept the contract given by (1). Given the manager's strategy, the shareholders obtain maximum possible surplus each period. Given they cannot do better than that, it is a best response for them to offer (1) each period. To summarize

Proposition 1. For the version of the game in which assistance is impossible and a high-cost (complex) project not worth pursuing (i.e., $c_{h} \geq b$ ), the equilibrium consists of the shareholders offering the contract given by (1) every period, the manager accepting, and the manager pursuing a project if and only if it is low cost (i.e., iff $c=c_{\ell}$ ).

The second case is $b>c_{h}$; that is, it is efficient to pursue projects regardless of cost (complexity). Because contracts cannot be contingent on cost, it might at first seem that the shareholders have only the following option: offer the contract given by (1), thereby forgoing any gains if $c=c_{h}$; or offer the contract

$$
y(\chi)=\left\{\begin{array}{l}
0, \text { if } \chi=0 \\
c_{h}, \text { if } \chi=1
\end{array},\right.
$$

thereby achieving gains if $c=c_{h}$, but leaving the manager with a sizable rent if $c=c_{\ell}$. (It is readily seen that always pursuing a project is a best response for the manager to (2).)

That view, however, overlooks that the game is repeated and, thus, an efficiency-wage argument (similar, e.g., to Shapiro and Stiglitz, 1984) applies. Specifically, suppose the shareholders wish the manager to pursue projects always. They offer compensation $y:\{0,1\} \rightarrow \mathbb{R}_{+}$each period along with the stipulation that the manager will be fired if she fails to pursue a project. Because the game is stationary and the shareholders possess no private information, if it is optimal for them to offer a particular contract in one period, it is optimal for them to offer that same contract in all periods. Moreover, if that contract will induce the manager to pursue a project when it's high cost, it must also do so when it's low cost. Consequently, the manager will pursue a project every period if her payoff this period facing a high-cost project plus the expected discounted value of future utility from maintained employment exceeds her utility from not pursuing it and losing her job:

$$
y(1)-c_{h}+\sum_{t=1}^{\infty} \delta^{t}(y(1)-\underbrace{\left(\phi c_{h}+(1-\phi) c_{\ell}\right)}_{=\text {expected cost } \equiv \mathbb{E} c}) \geq y(0),
$$


where, recall, $\phi$ is the probability a project is high cost.

Expression (3) is equivalent to

$$
y(1) \geq(1-\delta) y(0)+(1-\delta) c_{h}+\delta\left(\phi c_{h}+(1-\phi) c_{\ell}\right) .
$$

Because, under this contract, the shareholders pay $y(1)$ every period, they want it to be as small as possible subject to the constraint the manager always pursues a project (i.e., subject to (4)). It follows, therefore, that (4) will be an equality. It further follows that they will make $y(0)$ as small as possible, namely zero given the manager is protected by limited liability. To summarize:

Lemma 1. For the version of the game in which assistance is impossible, if the shareholders wish to induce the manager to pursue a project every period, then they will offer the contract

$$
y(\chi)=\left\{\begin{array}{l}
0, \text { if } \chi=0 \\
\underbrace{\left(\phi c_{h}+(1-\phi) c_{\ell}\right)}_{=\mathbb{E} c}+(1-\delta)(1-\phi) \Delta, \text { if } \chi=1
\end{array}\right.
$$

and dismiss the manager if she fails to pursue a project. The manager earns an expected rent (utility in excess of her reservation utility of zero) equal to

$$
(1-\delta)(1-\phi) \Delta \equiv R
$$

Because (6) is positive, the manager will accept the contract given in (5).

Under the contract in (5), the shareholders' per-period profit is $b-y(1)$ or

$$
b-\mathbb{E} c-R ;
$$

that is, as makes sense, the shareholders' per-period profit is benefit less expected cost less expected rent paid the manager.

The shareholders choose between offering a contract that implements a project always or a contract that implements a project only when it is low cost. Expected per-period profit under the latter, utilizing the contract in (1), is $(1-\phi)\left(b-c_{\ell}\right)$. It follows that the latter is less than the former when $(1-\phi)\left(b-c_{\ell}\right)$ is less than (7), which is true if the expected surplus gain derived from implementing a project always exceeds the manager's rent; that is, if $\phi\left(b-c_{h}\right) \geq R$. Equivalently, if

$$
b \geq c_{h}+(1-\delta) \frac{1-\phi}{\phi} \Delta .
$$

To summarize:

Proposition 2. For the version of the game in which assistance is impossible, the following holds:

(i) If the benefit of a project, $b$, does not exceed the high-cost level (i.e., $b \leq$ $c_{h}$ ), then, in equilibrium, projects are pursued only if low cost (i.e., only if $c=c_{\ell}$ ); full efficiency is attained; and all surplus is captured by the shareholders. 
(ii) If the benefit of a project exceeds the high-cost level, but by an insufficient amount-specifically, if $b$ is less than the righthand side of (8)-then, in equilibrium, projects are pursued only if low cost; less than full efficiency attains; but all realized surplus is captured by the shareholders (i.e., the manager obtains no rent).

(iii) If the benefit of a project exceeds the high-cost level by a sufficient amountspecifically, (8) holds-then projects are pursued always; full efficiency is attained; but the shareholders fail to capture all the surplus (i.e., the manager earns a rent).

Intuitively, when $c_{h}<b$, the shareholders face a tradeoff between efficiency and the rent they must pay the manager. ${ }^{9}$ There is little gain in efficiency when $b$ is close to $c_{h}$; hence, rent considerations dominate and the shareholders forgo inducing projects when $c=c_{h}$. When $b$ is large relative to $c_{h}$, considerable surplus is created even pursuing a high-cost project; enough surplus, in fact, to make it worthwhile to pay the manager a rent.

\section{Potential Cross-Firm Assistance without Side Pay- MENTS}

Return, now, to the assumption that managers can request cross-firm assistance when they have high-cost (complex) projects.

As an initial pass, I limit attention to a setting in which no cross-firm payments are possible. Consequently, any impetus one firm's manager has to help the other firm's stems from the expectation that such help will be reciprocated. In other words, cross-firm cooperation is sustained via reputation in a repeatedgame setting. In particular, assume that a given manager will punish another's refusal to provide assistance by never providing assistance herself in any future period. That is here - and throughout the paper-assume enforcement of relational contracts is via grim-trigger strategies. ${ }^{10}$

The possibility of a breakdown in cooperation (provision of assistance) raises the question of what happens if the shareholders offer contracts anticipating cross-firm cooperation, but a manager defects by not cooperating? Recall that the shareholders don't observe whether cooperation occurs. A reasonable assumption in this regard is

Assumption 1. If the shareholders expect cooperation and their manager fails to pursue a project, she is dismissed and the shareholders believe, going forward, that there will be no cooperation (provision of mutual assistance).

Within a period, assume that requests for assistance are made simultaneously and, similarly, the managers provide (or not) assistance simultaneously.

\footnotetext{
${ }^{9}$ This rent is the usual information rent that arises in hidden-information models of agency.

${ }^{10}$ The analysis is readily extended to encompass finite-length punishments. That extension would not, however, have a substantive effect on the results and, thus, is not considered here for the sake of brevity.
} 
In other words, within a period, one manager's decision to request assistance cannot be contingent on another's request and, similarly, her decision to provide assistance cannot be contingent on the other's provision of assistance.

Suppose the universal expectation is that assistance will be granted if requested. Consider a given manager's decision. If she grants assistance, her payoff is

$$
y(1)-c_{\ell}-a+\sum_{t=1}^{\infty} \delta^{t}\left(y(1)-c_{\ell}-\phi a\right),
$$

where the expression in parentheses reflects that projects are always taken (so she receives $y(1)$ in pay); her own project is either low cost or she receives assistance (so her own cost is $c_{\ell}$ ); and, with probability $\phi$, she will be asked to provide assistance (at a cost to her of $a$ ). If she reneges on her implicit promise of assistance, then she saves the current cost $a$; but, because she will never receive assistance again, the present value of her future expected utility, $U_{0}$, will be different (I derive $U_{0}$ shortly). Hence, she will provide assistance if

$$
y(1)-c_{\ell}-a+\sum_{t=1}^{\infty} \delta^{t}\left(y(1)-c_{\ell}-\phi a\right) \geq y(1)-c_{\ell}+\delta U_{0} .
$$

Equivalently, if

$$
y(1) \geq c_{\ell}+\phi a+\frac{1-\delta}{\delta} a+(1-\delta) U_{0} .
$$

Because a manager is free to quit, her continuation utility cannot be less than her reservation utility, zero; that is, $U_{0} \geq 0$. It, thus, follows from (9) that $y(1)>c_{\ell}+\phi a$ : if a manager is to be induced to give assistance, then she must earn a rent, in expectation, each period. Because it also follows that $y(1)>c_{\ell}$, if there is a breakdown in mutual-assistance giving, then a manager has an incentive to pretend to the shareholders that such a breakdown has not occurred; at least until she draws a high-cost project. This last insight means

$$
\begin{aligned}
U_{0} \geq \sum_{t=0}^{\infty} \delta^{t}(1-\phi)^{t}((1-\phi) & \left.\left(y(1)-c_{\ell}\right)+\phi y(0)\right) \\
= & \frac{1}{1-(1-\phi) \delta}\left((1-\phi)\left(y(1)-c_{\ell}\right)+\phi y(0)\right) .
\end{aligned}
$$

The alternative is for the manager to pursue all projects forever after; were she to do so, her expected lifetime utility is

$$
\sum_{t=0}^{\infty} \delta^{t}(y(1)-\mathbb{E} c)=\frac{1}{1-\delta}\left((1-\phi)\left(y(1)-c_{\ell}\right)+\phi\left(y(1)-c_{h}\right)\right) .
$$

If the righthand-side expression in (11) exceeds that last expression in (10), then $U_{0}$ equals the expression in (11); otherwise, it is equal to the last expression in (10). 
Observe that $y(0)$ is either irrelevant (if $U_{0}$ is given by $(11)$ ) or reducing it relaxes the constraint (9) (if $U_{0}$ is given by (10)). Either way, it follows that $y(0)$ can or will be set to 0 , the minimum possible value given the manager's limited liability.

If $U_{0}$ is given by (11), then simple algebra reveals that $y(1)$ cancels out of (9). This makes sense: if a manager always pursues a project, regardless of whether assistance will be forthcoming, then her payment for undertaking her own project is irrelevant to her decision to provide assistance. Further algebra reveals that (9) is, in this case, equivalent to

$$
\mathbb{E} c \geq c_{\ell}+\phi a+\frac{1-\delta}{\delta} a
$$

that is, her expected per-period cost of action absent assistance must exceed her expected per-period cost of action with assistance plus a term, $(1-\delta) a / \delta$, which reflects the cost of actually providing assistance today. Because this case is premised on the manager pursuing all projects even absent assistance, Lemma 1 pertains with regard to the minimum level at which the shareholders can set $y(1)$; it will be given by (5). If this case represents equilibrium, then it follows that shareholders gain nothing from the managers' ability to provide mutual assistance vis-à-vis a setting in which such aid was impossible. To summarize:

Lemma 2. In equilibrium, the shareholders will set compensation for not pursuing a project, $y(0)$, to zero. If compensation for pursuing a project, $y(1)$, is set so that a manager will pursue a project always, regardless of whether assistance will be forthcoming, then that compensation is the same as it would be if no assistance were possible. In this situation, assistance is granted in equilibrium if expression (12) holds true and not if it doesn't.

If, instead, $U_{0}$ is given by $(10)$, then (9) can be rewritten as

$$
y(1) \geq c_{\ell}+\phi a+a \frac{(1-(1-\phi) \delta)^{2}-\delta \phi^{2}}{\delta \phi} .
$$

Let $y_{I}(\cdot)$ denote the contract given in expression (5). Define $y_{A}(0)=0$ and let $y_{A}(1)$ equal the righthand side of (13). It follows that if the shareholders want projects pursued always, then they will offer $y(0)=0$ and $y(1)=$ $\min \left\{y_{I}(1), y_{A}(1)\right\}$. To determine what $y(1)$ will be, it is useful to define $\theta=$ $\Delta / a$. Because assistance is efficient - recall $a<\Delta$-it follows that $\theta>1$. Observe that

$$
y_{I}(1)=c_{\ell}+(1-(1-\phi) \delta) \theta a \text { and } y_{A}(1)=c_{\ell}+\frac{(1-(1-\phi) \delta)^{2}}{\delta \phi} a .
$$

It follows that it cheaper to use the $y_{I}(\cdot)$ contract than the $y_{A}(\cdot)$ contract if

$$
\theta<\frac{1-(1-\phi) \delta}{\phi \delta}
$$


Note (12), the condition for the managers to provide mutual assistance even if all projects are to be pursued even in the absence of assistance, entails

$$
\theta \geq \frac{1-(1-\phi) \delta}{\phi \delta}
$$

To summarize:

Lemma 3. Suppose assistance is feasible and shareholders wish to induce managers to choose projects always. Then if the additional cost of pursuing a complex (hard) project alone (i.e., $\Delta$ ) is low enough relative to the cost of assistance-specifically if (14) holds-then the shareholders will use the contract given in Lemma 1 and the managers will not provide assistance in equilibrium. If that additional cost (i.e., $\Delta$ ) is great enough relative to the cost of assistance-specifically if (15) holds - then the shareholders will use the contract $\left\langle y_{A}(0), y_{A}(1)\right\rangle$ and the managers will provide assistance in equilibrium.

Intuitively, if the expected cost savings the manager realizes by receiving assistance is small relative to the expected cost of having to do all projects herself, then she will have no incentive to provide assistance: the immediate cost of providing assistance today outweighs the future expected benefits of reciprocity from the other manager. If the manager cannot be induced to provide assistance, then the shareholders are in the same situation they were when assistance was infeasible.

If assistance can never be induced, then full efficiency can never be achieved: even if condition (8) holds, so all projects are implemented, it is more efficient for high-cost projects to be implemented with assistance than without. If assistance is induced, then full efficiency is achieved; however, because $y_{A}(1)>c_{\ell}+\phi a$ (recall (9)), the manager earns a rent. That rent drives a wedge between what is optimal for the shareholders and what is efficient. In particular, it is possible that the shareholders' expected profits are greater implementing only low-cost projects, which they do by offering $y(1)=c_{\ell}$ and $y(0)=0$, than implementing all projects.

To summarize:

Proposition 3. When assistance is feasible, one of three equilibria exists. Specifically,

(i) if the benefit from project implementation is insufficiently large-that is,

$$
b<\frac{1}{\phi} \min \left\{y_{A}(1), y_{I}(1)\right\}-\frac{1-\phi}{\phi} c_{\ell}
$$

- then shareholders offer the contract $y(1)=c_{\ell}$ and $y(0)=0$, projects are implemented only if low cost, efficiency is not achieved, but all realized surplus is captured by the shareholders;

(ii) if the benefit from project implementation is sufficiently large (i.e., the inequality in (16) is reversed), then shareholders offer the contract $y(1)=$ $\min \left\{y_{A}(1), y_{I}(1)\right\}$ and $y(0)=0$, all projects are implemented, and the manager earns a rent (not all surplus is captured by the shareholders); 
(iii) whether efficiency is achieved in this latter case depends on whether the managers can sustain cooperation (mutual assistance); that is, if (15) holds. If it does, then efficiency is achieved and $y(1)=y_{A}(1)$; if it doesn't, then efficiency is not achieved and $y(1)=y_{I}(1)$.

\section{5 "Perfect" Wining \& Dining}

Suppose, now, that the shareholders of each firm can provide their manager with funds to "wine and dine" or otherwise provide some compensation to the other firm's manager. Suppose, too, that this wining and dining is "perfect" in the following sense:

(i) auditing of entertainment expenses is sufficiently good that it is not possible for the manager of a given firm to pocket or otherwise use these funds for her own purposes; that is, she either spends them on the other manager or they remain unspent; and

(ii) the manager of each firm is willing to commit to wine and dine on a quid pro quo basis only; that is, she wine and dines the other firm's manager in period $t$ if and only if that manager provided her assistance in period $t-1$.

Assume here, and throughout, that a dollar spent on wining and dining (entertaining) a manager yields her a dollar of benefit. To be sure, one can imagine scenarios in which expenditure and benefit diverge (with either being the larger), but such a complication does not substantively change the analysis. For the sake of brevity, I have, therefore, chosen to ignore it.

Assuming perfect wining \& dining means a manager cannot privately benefit from the funds allocated her for entertainment; hence, she has no incentive to renege on the quid pro quo promise of entertaining the other firm's manager in the current period if she received assistance from him in the previous period. Let $w$ denote the expenditure on wining and dining the other firm's manager. For him to judge this a worthwhile exchange, it must be that $\delta w \geq a$; that is, the reward, properly discounted, must be at least equal to his cost of providing assistance. Because shareholders wish to minimize their costs, they will set $w=a / \delta$. Observe that the present cost to the shareholders of ensuring their manager obtains assistance today is $\delta w=a$; that is, the shareholders' cost exactly equals the cost of assistance. It follows, therefore, that the shareholders can achieve the first best: they pay their own manager according to the contract

$$
y(\chi)=\left\{\begin{array}{l}
0, \text { if } \chi=0 \\
c_{\ell}, \text { if } \chi=1
\end{array}\right.
$$

and allow her to spend $w$ on wining and dining. All projects are undertaken, either without assistance if low cost and with assistance if high cost, which is efficient (recall $b>c_{\ell}+a$ ). Further, because no manager earns a rent in presentvalue terms, it must be that all surplus is being captured by the shareholders. To summarize 
Proposition 4. Suppose that perfect wining and dining is feasible. Then full efficiency is achieved in every period and the shareholders capture 100\% of that surplus (i.e., the shareholders realize the first-best outcome).

\section{Wining and Dining With Collusion}

Recall that the shareholders cannot observe whether their manager received assistance or not. Consequently, they are vulnerable to collusion between managers: each manager claims to always be receiving assistance so that she always "pays" the other $w$ in the next period. Suppose, now, that managers are inclined to collude in this fashion (i.e., premise (ii) of perfect wining and dining is not met).

If a manager expects to receive $w$ regardless of whether she provided assistance or not, then the only motivation she has to provide assistance today is to avoid punishment in the future; that is, the end of cooperation. The end of cooperation means not receiving assistance in the future and, also, the end of wining and dining. Under the contract given by (17), the end of cooperation means, therefore, zero utility forever after. Cooperating means a future discounted utility of

$$
\sum_{t=1}^{\infty} \delta^{t}\left(y(1)-c_{\ell}+w-\phi a\right)=\sum_{t=1}^{\infty} \delta^{t}(w-\phi a)=\frac{\delta}{1-\delta}(w-\phi a),
$$

where the first equality follows because $y(1)=c_{\ell}$. It follows that cooperation is sustained if

$$
-a+\frac{\delta}{1-\delta}(w-\phi a) \geq 0 .
$$

Assuming they wish to induce cooperation, each firm will wish to minimize its expenditure $y(1)+w$ subject to (18). Hence,

$$
y(1)+w=c_{\ell}+\frac{1-(1-\phi) \delta}{\delta} a=c_{\ell}+\phi a+\frac{1-\delta}{\delta} a .
$$

Observe the manager earns a rent of $(1-\delta) a / \delta$ each period.

Comparing $y(1)+w$ given by (19) with $y_{A}(1)$, the former is readily seen to be less. ${ }^{11}$ Hence, if the shareholders wish to induce assistance, they do better to do so via wining and dining - despite the problem of collusion - than via a sufficiently high wage (i.e., via an efficiency-wage effect).

Intuitively, when they induce mutual assistance without wining and dining, the shareholders must account for the possibility that the manager has an incentive to pretend it's "business as usual" after the breakdown of mutual assistance until the point that she draws a high-cost project, because she earns a sizable

\footnotetext{
${ }^{11}$ Observe

$$
y_{A}(1)-y(1)-w=a \frac{1-(1-\phi) \delta}{\delta}\left(\frac{1-(1-\phi) \delta}{\phi}-1\right),
$$
}

where the term in large parentheses is positive because $1-\delta+\phi \delta>\phi$ given $\phi<1$. 
rent on each low-cost project $\left(\right.$ i.e., $\left.y_{A}(1)>c_{\ell}\right)$. In essence, the penalty for a breakdown in mutual assistance is delayed in expected value terms. In contrast, with wining and dining, the shareholders eliminate that incentive to keep things going: $y(1)=c_{\ell}$, so there are no future rents should mutual assistance cease. Hence, the penalty for failing to provide mutual assistance is greater, which means the shareholders must leave the manager less of a total rent (pay plus wining and dining less cost of actions) than they would in the absence of wining and dining.

To summarize:

Proposition 5. If, in the absence of wining and dining, the shareholders would optimally wish to induce cross-firm assistance, then they are strictly better off with wining and dining even if the managers can collude.

Because of the rent term in (19), it is possible that the shareholders will not wish to induce assistance. Comparing $y(1)+w$ given by (19) with $y_{I}(1)$, if the cost differential between high and low-cost projects is sufficiently small relative to the cost of assistance - specifically, if $\theta<1 / \delta$ - then the shareholders do better either having their manager pursue all projects on her own or pursuing only low-cost projects. The possible equilibrium outcomes are, thus, low-cost projects only being implemented (which is inefficient when assistance is possible); or all projects being implemented, but without assistance (also inefficient if assistance is possible, plus which this entails a rent for the managers); or all projects being implemented, with assistance if need be (efficient, but this entails a rent for the managers). Regardless of equilibrium, the shareholders can't achieve the first-best outcome when the managers can collude over wining and dining (i.e., when wining and dining is not "perfect").

Proposition 6. If the managers can collude with respect to wining and dining (i.e., entertain each other every period independent of whether assistance was called for in the previous period), then the shareholders cannot achieve the firstbest outcome. The resulting outcome is efficient if assistance is induced and not if it isn't.

\section{Wining and Dining With Potential Embezzlement}

Condition (i) for perfect wining and dining was that the manager could not embezzle funds set aside for entertainment. In reality, control of expenses connected to entertainment is notoriously imperfect. ${ }^{12}$ In this section, consider the limiting case in which there is no auditing: a manager can pocket the amount, $w$, available for entertainment without any risk of detection by her firm. For the

\footnotetext{
${ }^{12}$ According to the Association of Certified Fraud Examiners (2012), 14.5\% of "asset misappropriation" involves fraudulent expense reimbursement. The median loss in detected cases was $\$ 26,000$. Although this category includes fraudulent entertainment expenses (including, as the Association's report puts it, "nonexistent meals"), it also includes other expenses, such as travel, so abuse of entertainment budgets per se is a subset of these cases.
} 
time being, return to the assumption of no collusion (i.e., condition (ii) of perfect wining and dining is assumed to hold); that assumption will be reconsidered at the end of this section.

Although her own firm can't detect her embezzlement, the manager of the other firm will be aware that he didn't receive any quid pro quo for his assistance. He can punish the embezzling manager by withholding cooperation in the future. In other words, embezzlement by one manager leads to the breakdown of mutual assistance.

Only settings in which the shareholders can benefit by inducing assistance are of interest. Hence, they will not set $y(1)$ so that all projects are pursued regardless of whether assistance will be forthcoming or not. In other words, future expected lifetime utility, $U_{0}$, should mutual assistance collapse is given by the righthand side of (10). Employing by now familiar reasoning, $y(0)=0$; hence,

$$
U_{0}=\frac{1}{1-(1-\phi) \delta}(1-\phi)\left(y(1)-c_{\ell}\right) .
$$

As was implicit in the analysis of Section 5, the timing within a period is that a given manager decides whether to entertain the other manager, assuming the other manager provided assistance in the previous period, before assistance requests and decisions are made for the current period. Consequently, if a manager embezzles that period's entertainment budget, the expected present value of her lifetime utility is

$$
w+U_{0} .
$$

If she entertains the other manager (doesn't embezzle), then the expected present value is

$$
\frac{1}{1-\delta}\left(y(1)-c_{\ell}+\phi(\delta w-a)\right) .
$$

The manager will not embezzle provided (20) does not exceed (21).

The manager also must be willing to provide assistance:

$$
-a+\delta w+\frac{\delta}{1-\delta}\left(y(1)-c_{\ell}+\phi(\delta w-a)\right) \geq \delta U_{0} .
$$

In setting $y(1)$ and $w$, the shareholders wish to minimize the present discounted value of their per-period payment,

$$
y(1)+\delta \phi w,
$$

subject to expression (20) not exceeding (21) and to expression (22) holding.

Lemma 4. Suppose there is a potential for entertainment-expense fraud. Assuming they wish to induce mutual assistance, the shareholders will offer the compensation contract

$$
y(\chi)=\left\{\begin{array}{l}
0, \text { if } \chi=0 \\
c_{\ell}+\frac{1}{2} \times \frac{(1-(1-\phi) \delta)^{2}}{\delta \phi} a, \text { if } \chi=1
\end{array}\right.
$$


and set the entertainment budget at

$$
w=\frac{1}{2} \times \frac{a}{\delta} .
$$

Proof: See appendix.

Because, as the proof of Lemma 4 makes clear, a contract with $y(1)=y_{A}(1)$ and $w=0$ satisfies both constraint (22) and, trivially, the no-embezzlement constraint (i.e., that (21) not be less than (20)), the shareholders are better off-assuming they wish to induce mutual assistance - than they were when wining and dining was impossible (i.e., in Section 4). ${ }^{13}$ To summarize:

Proposition 7. If, in the absence of wining and dining, the shareholders would optimally wish to induce cross-firm assistance, then they are strictly better off with wining and dining even if managers can potentially embezzle their entertainment budgets (provided they cannot also collude).

It is readily shown that

$$
y(1)+\delta \phi w=c_{\ell}+\phi a+\frac{(1-\delta)^{2}+2(1-\delta)(1-\phi) \delta \phi}{2 \delta \phi},
$$

from which it follows that a manager earns a rent, in expectation, in equilibrium. As before, this rent drives a wedge between total surplus and the shareholders' profits and, correspondingly, can lead them to pursue a less efficient, but more profitable strategy (i.e., either implementing low-cost projects only or inducing all projects, but without mutual assistance). To conclude:

Proposition 8. If the managers can potentially embezzle their entertainment budget, then the shareholders cannot achieve the first-best outcome. The resulting outcome is efficient if assistance is induced and not if it isn't.

Finally, what if neither condition for perfect wining and dining is met; that is, what if managers can both collude with each other and embezzle their entertainment budgets? Observe, in this case, it is as if each manager receives an additional per-period payment of $w$ on a non-contingent basis (regardless of how collusion is conceived, the situation is equivalent to the managers' agreeing

${ }^{13}$ This can also be seen by direct calculation:

$$
\begin{aligned}
y(1)+\delta \phi w=c_{\ell}+ & \frac{(1-(1-\phi) \delta)^{2}+\phi^{2} \delta^{2}}{2 \delta \phi} a \\
=c_{\ell}+\frac{2(1-(1-\phi) \delta)^{2}-(1-\delta)^{2}-2(1-\delta) \phi \delta}{2 \delta \phi} a & \underbrace{c_{\ell}+\frac{(1-(1-\phi) \delta)^{2}}{\delta \phi}}_{y_{A}(1)} a-\underbrace{\frac{(1-\delta)^{2}+2(1-\delta) \phi \delta}{2 \delta \phi} a}_{>0} .
\end{aligned}
$$


that each will pocket her own entertainment budget each period). But if $w$ is received on a non-contingent basis, then it is as if side payments are infeasible. The situation is, therefore, identical to that of Section 4: if the shareholders wish to induce mutual assistance, then they will pay total compensation each period equal to $y_{A}(1)$; the division of which into salary (i.e., $y$ ) and a to-be-embezzled entertainment budget (i.e., $w$ ) is indeterminate. This last point means that although the shareholders cannot benefit from wining and dining, they are not made worse off by it either. To summarize:

Proposition 9. If managers can both collude with each other and embezzle their entertainment budgets, then the shareholders cannot benefit from wining and dining (although they don't lose from it either). The equilibrium outcome, in terms of profits, projects pursued, and provision of mutual assistance, will be the same as in Proposition 3.

\section{Concluding Discussion}

This paper provides a rationalization for firms funding their managers wining and dining (more, generally, gift or favor exchange): wining \& dining, even when itself the source of agency problems, can be a less expensive way for firms to induce their managers to cooperate with each other than utilizing standard incentive contracts. In particular, because the managers can observe what the firms' owners cannot, delegating to the managers the authority to make discretionary transfers to each other allows the owners to avoid or reduce the informational rents they would otherwise be stuck paying their managers.

As alluded to in the introduction, the paper can be read narrowly as being about wining \& dining or more broadly as being about delegating the authority over discretionary inter-firm payments to managers. A narrower reading necessitates a brief consideration of alternative explanations of wining \& dining. An obvious alternative is that wining and dining is simply a form of bribery: the manager (firm) doing the wining \& dining does so because she (it) seeks to induce the manager being wined and dined to take an action beneficial to her (it), but at odds with what that manager's employer would wish for him to do. Although one certainly cannot rule out some wining \& dining as constituting bribery in this sense, there are difficulties with imagining all wining \& dining is: if it were, then why would it ever be seen as acceptable? Indeed, why wouldn't it be illegal, as cash bribes (i.e., kickbacks) essentially are? ${ }^{14}$ Further, as noted in the introduction, organizations that are worried about their employees being bribed or improperly influenced could - and in fact do - place prohibitions on their employees being wined and dined.

One could also envision a signaling story to explain wining \& dining. As Hermalin (1998), among others, notes, giving gifts to uninformed players is a way for an informed player to make credible her claims (e.g., about the value of proposed joint project, the quality of the good she is selling, etc.). While

\footnotetext{
${ }^{14}$ Commercial bribery is illegal in 25 us states (Greene, 1999). Although no Federal statute directly prohibits it, it can be prosecuted at the Federal level as mail fraud (Greene).
} 
signaling could explain some wining \& dining, such an explanation is less than ideal for explaining why wining \& dining tends to occur repeatedly in ongoing relationships: unless the signaler's private information is changing over time, she need signal only once.

Results in experimental economics on gift exchange, which find that gifts by one player can induce cooperative responses from another, ${ }^{15}$ might seem to offer another explanation for wining \& dining. Yet, I would argue those results are highly complementary with the model set forth above. In particular, the results from that literature are consistent with the basic notion of this paper that contingent gift giving by managers is a cheaper way for their principals to induce cooperation than incentive contracts; that in-kind gifts might cause their recipients to be more cooperative than the gifts' monetary value would suggest (as in Kube et al., for example) only strengthens the case for wining \& dining as a substitute for direct incentives. Furthermore, such findings could also address a potential objection to the model, namely that meals, even at the nicest restaurants, might not be adequate compensation for providing assistance.

That last objection can also be addressed by noting that wining \& dining need not be taken literally; in particular, there are far more valuable gifts (e.g., positions on boards of directors, employing family members) that can be bestowed.

Reading the paper more broadly - that is, as it being about delegating to managers decisions on discretionary inter-firm payments - the paper can be seen as an attempt to break open the "black box" of inter-firm cooperation. In particular, modeling of such cooperation (as, for instance, in Baker et al., 2002 or Doornik, 2006) has, to the best of my knowledge, treated the firms as unitary actors. In reality, of course, each has its own internal agency problems and how those agency problems interact with the principals' desires to foster cooperation is important to understand. To be sure, this paper only scratches the surface of such issues, but it is to be hoped that it helps contribute to a deeper understanding of inter-firm cooperation.

\section{Appendix A: Proofs Not Given in Text}

Proof of Lemma 4: Rewrite the constraint that (20) not exceed (21) as

$$
y(1) \geq \underbrace{c_{\ell}+(1-\delta+\phi \delta) a}_{\mathbf{Y}_{A}}+\frac{(1-\delta)^{2}-\delta^{2} \phi^{2}}{\phi} w .
$$

Constraint (22) can be rewritten as

$$
y(1) \geq \underbrace{c_{\ell}+\frac{(1-\delta+\phi \delta)^{2}}{\delta \phi}}_{\mathbf{Y}_{B}} a-\frac{(1-\delta+\phi \delta)^{2}}{\phi} w .
$$

\footnotetext{
${ }^{15}$ See, for instance, Fehr et al. (1998) or Kube et al. (2012); although also see Charness et al. (2004) for a critique of this literature.
} 
Treating the two inequalities as equalities, we have two lines in $w-y$ space, with the set of $(w, y(1))$ pairs satisfying both constraints lying on or above the upper envelope of the two lines. Because

$$
1-\delta+\delta \phi>\delta \phi
$$

$\mathrm{Y}_{A}<\mathrm{Y}_{B}$. Hence, until the two lines intersect at the point

$$
w=\frac{a}{2 \delta} \text { and } y(1)=c_{\ell}+\frac{(1-\delta+\phi \delta)^{2}}{2 \delta \phi} a,
$$

only (25) is relevant (i.e., any $(w, y(1)), w \leq a /(2 \delta)$, satisfying (25) will also satisfy (24)). To the right of that point, only (24) is relevant. The shareholders expected present value per-period cost is $y(1)+\delta \phi w$; hence, the slope of an iso-cost line is $-\delta \phi$. Observe

$$
-\delta \phi>-\frac{(1-\delta+\phi \delta)^{2}}{\phi},
$$

because

$$
\delta \phi^{2}<((1-\delta)+\delta \phi)^{2}=(1-\delta)^{2}+2(1-\delta) \delta \phi+\delta^{2} \phi^{2}
$$

given

$$
\phi(1-\delta) \delta \phi<2(1-\delta) \delta \phi .
$$

That is, the slope of an iso-cost line is less steep (less negative) than the line defined by (25). Consequently, any point on that line for $w \in[0, a /(2 \delta))$ is dominated by the point given in (26). Observe

$$
-\delta \phi<\frac{(1-\delta)^{2}-\delta^{2} \phi^{2}}{\phi}
$$

because

$$
-\delta(1-\delta) \phi^{2}<(1-\delta)^{2} .
$$

That is, the slope of an iso-cost line is steeper (more negative) than the line defined by (24). Consequently, any point on that line for $w \in(a /(2 \delta), \infty)$ is dominated by the point given in (26). This establishes that the point given in (26) minimizes the present value of the shareholders' per-period expected cost. Finally, note that $1-\delta+\phi \delta=1-(1-\phi) \delta$.

\section{REFERENCES}

Association of Certified Fraud Examiners, Report to the Nations on Occupational Fraud and Abuse: 2012 Global Fraud Study 2012.

Baker, George P., Robert Gibbons, and Kevin J. Murphy, "Relational Contracts and the Theory of the Firm," Quarterly Journal of Economics, February 2002, $117(1), 39-84$. 
Banerjee, Abhijit, Rema Hanna, and Sendhil Mullainathan, "Corruption," in Robert S. Gibbons and John Roberts, eds., The Handbook of Organizational Economics, Princeton, NJ: Princeton University Press, 2013.

Charness, Gary, Guillaume R. Frechette, and John H. Kagel, "How Robust is Laboratory Gift Exchange?," Experimental Economics, 2004, 7, 189-205.

Che, Yeon-Koo and Seung-Weon Yoo, "Optimal Incentives for Teams," American Economic Review, June 2001, 91 (3), 525-541.

Clotfelter, Charles T., "Tax-Induced Distortions and the Business-Pleasure Borderline: The Case of Travel and Entertainment," American Economic Review, December 1983, 73 (5), 1053-1065.

Doornik, Katherine, "Relational Contracting in Partnerships," Journal of Economics and Management Strategy, Summer 2006, 15 (2), 517-548.

Fehr, Ernst, Erich Kirchler, Andreas Weichbold, and Simon Gächter, "When Social Forces Overpower Competition: Gift in Experimental Labor Markets," Journal of Labor Economics, April 1998, 16 (2), 324-351.

Greene, Craig L., "Bribery, Kickbacks and Payoffs," www.mcgoverngreene. com/archives/archive_articles/Craig_Greene_Archives/bribery-kickbackspayoffs.html 1999.

Hermalin, Benjamin E., "Toward an Economic Theory of Leadership: Leading by Example," American Economic Review, December 1998, 88 (5), 11881206.

Itoh, Hideshi, "Incentives to Help in Multi-Agent Situations," Econometrica, May 1991, 59 (3), 611-636.

J.P. Morgan, Corporate TEEE Spend Benchmarks 2011.

Katz, Michael L., "Game-Playing Agents: Unobservable Contracts as Precommitments," RAND Journal of Economics, 1991, 22 (3), 307-328.

_-, "Observable Contracts as Commitments: Interdependent Contracts and Moral Hazard," Journal of Economics 83 Management Strategy, 2006, 15 (3), $685-706$.

Kube, Sebastian, Michel André Maréchal, and Clemens Puppe, "The Currency of Reciprocity: Gift Exchange in the Workplace," American Economic Review, June 2012, 102 (4), 1644-1662.

Malcomson, James M., "Relational Incentive Contracts," in Robert S. Gibbons and John Roberts, eds., The Handbook of Organizational Economics, Princeton, NJ: Princeton University Press, 2013. 
Mookherjee, Dilip, "Incentives in Hierarchies," in Robert S. Gibbons and John Roberts, eds., The Handbook of Organizational Economics, Princeton, NJ: Princeton University Press, 2013.

Sappington, David E.M., "Limited Liability Contracts between Principal and Agent," Journal of Economic Theory, February 1983, 29 (1), 1-21.

Shapiro, Carl and Joseph E. Stiglitz, "Equilibrium Unemployment as a Worker Discipline Device," American Economic Review, June 1984, 74 (3), 433-444.

Tirole, Jean, "Hierarchies and Bureaucracies: On the Role of Collusion in Organizations," Journal of Law, Economics, ES Organization, Fall 1986, 2 (2), 181-214. 